DOI: http://dx.doi.org/10.14201/0AQ02875568

\title{
THE IMPORTANCE OF DIGITAL TRANSFORMATION. INCIDENCE OF THE DIGITAL ECONOMY AND SOCIETY INDEX (DESI) IN THE GDP OF THE EUROZONE ECONOMIES
}

\author{
Javier Parra; Eugenia Pérez; Jorge GonzÁlez \& Juan Manuel Corchado \\ BISITE Digital Innovation Hub, University of Salamanca, \\ Edificio Multiusos I+D+I, 37007, Salamanca, Spain \\ javierparra@usal.es
}

ABSTRACT: In recent years, numerous researches have studied the relationship between the so-called technological indicators and the social development of different countries.

The main motivation of this study has been to find out whether there is a relationship between the variables of the DESI technological indicator and this year's GDP per capita. The existence of such a relationship has been identified and it has been discovered that it is directly related to the use of internet services by citizens and to the implementation of technology in companies.

KEYWORDS: DESI; GDP; technology; digital transformation.

\section{Introduction}

Over the past few years, companies in almost every industry have carried out a series of initiatives to develop new digital technologies and explore their benefits [1-12]. Information and Communication Technologies (ICT) are the merger between new digital technologies and traditional industrial production, leading to the emergence of what we know today as Industry 4.0 [13-20].

The concept of industry 4.0 has allowed to transform factories into intelligent environments where information, objects, and people are connected thanks to the convergence between the physical and the virtual world through cyber-physical systems [21-29]. 
Advanced economies have experienced significant technological change. The developments that were made since the twentieth century onward eventually led to the emergence of Industry 4.0. The scientific progress that has been made over the years, has allowed for a significant fall in the price of technological capital [30-41].

Unlike the largest economies, such as Germany or the United States, some countries in the European Union have not been able to take advantage of all the benefits offered by the so-called digital revolution. The crisis in 2008 made governments implement austere fiscal policies which reduced spending on research and development [42-50] and business investment. Nevertheless, the situation changed noticeably in 2014. In that year, the digitalization became the driver of several economies [51-56], in the case of Spain, it was responsible for a $30 \%$ increase in added value in 2015 [57-60].

In recent years, digital transformation has become an engine of growth for the entire Eurozone. For this reason, the current work focuses on the study of the relationship between the GDP per capita of the Eurozone countries and The Digital Economy and Society Index (DESI) during the period 2015 2018.

\subsection{Digital transformation. A global concept}

Digital native companies are the ones that have best responded to digital transformation, they increased their profits and have been able to implement new business models more efficiently [61]. Despite the fact that technological and digital advances have enabled interconnectivity, digital transformation has not spread uniformly around the world and not all countries benefited from it equally. One of the main reasons for which this inequality exists is the digital divide. This is a term used to describe the unequal opportunity to access technology and it focuses especially on the varying conditions of Internet access [62-68] in different parts of the world.

Given the possibilities offered by digital transformation and the technological inequality between countries, at the last G20 summit, digital transformation has been included in the global agenda. It is hoped that thanks to this, more inclusive and sustainable growth will be achieved for all countries worldwide [69-70]. 


\subsection{The Digital Economy and Society Index (DESI)}

The Digital Economy and Society Index, DESI, is a composite indicator that measures the digital performance of Europe. DESI is also responsible for investigating the digital competitiveness of the member states of the European Union. This index is elaborated annually by the European Commission [71].

The indicator of digital competitiveness is broken down into 5 components and their main implications:

- Connectivity: Measures the deployment of broadband infrastructure and its quality. It is measured according to 5 variables: Fixed ADSL, Mobile ADSL, fast broadband, ultra-fast broadband, broadband price index. For example, access to fast and ultrafast broadband services is a necessary condition for competitiveness.

- Human Capital: Measures the skills that are needed in order to take advantage of the possibilities offered by digital technology. It is measured according to 2 variables: Internet users' skills, advanced skills and development.

- Use of internet services by citizens: It represents a variety of online activities, such as the consumption of online content (videos, music, games, etc.), as well as online shopping and banking.

- Integration of digital technology by businesses: Measures the digitalization of companies and e-commerce. By adopting digital technologies, companies can improve efficiency, reduce costs and improve customer and business services.

- Digital public services: Measures the digitalization of public services, focusing on electronic administration and health. The modernization and digitalization of public services can generate efficiency gains for public administration, citizens and businesses alike (such as e-health and e-Government).

\section{Methodology}

\subsection{Population and sample}

Data on the GDP per capita and The Digital Economy and Society Index (DESI), have been obtained for 19 countries in the Eurozone, for the following time period 2015-2018. 
GDP per capita data comes from Eurostat [72] and is expressed in millions of euros at current prices, for each time period and country separately.

The Digital Economy and Society Index (DESI) data have been obtained from the reports of the European Commission that analyze the ranking of each country according to the DESI index [73-78].

\subsection{Variables}

The following variables have been selected for the analysis, so it is possible to observe, as anticipated, the incidence of DESI disaggregation in GDP:

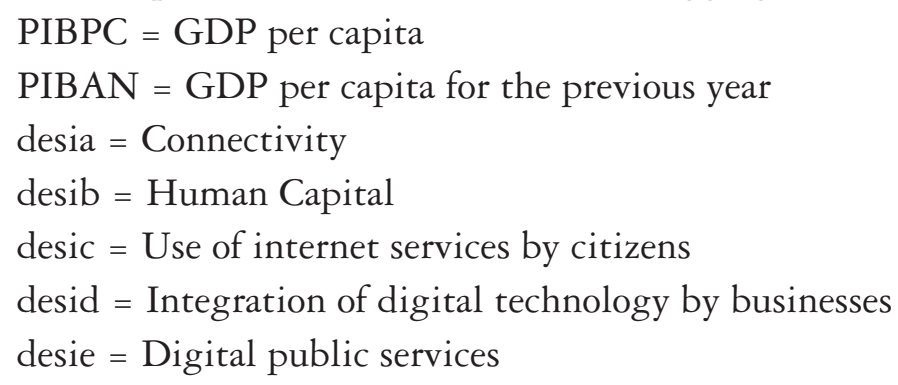

\subsection{Estimation techniques}

For the estimation of the model we have used panel data, combining cross sections for several periods of time.

Specifically, we have followed the methodology of applying fixed effects, this is the most elementary and consistent methodology and the model to be estimated is:

$\log (\mathrm{PIBPC})=\beta_{1} \log (\mathrm{PIBAN})+\beta_{2} \log ($ desia $)+\beta_{3} \log ($ desib $)+\beta_{4} \log (\mathrm{de}-$ sic $)+\beta_{5} \log ($ desid $)+\beta_{6} \log ($ desie $)+u_{\mathrm{i}, \mathrm{t}}$

We have elaborated the expression of the model and we have chosen to adopt logarithms because they facilitate the comprehension of results. In the model, we take into account this year's and last year's GDP per capita of each country, considering the 2015-2018 period and all the disaggregated components of the DESI index during this time period.

We have used the $\mathrm{R}$ software to estimate the model, a free programming software, oriented to statistical analysis, which allows to design econometric models and analyze them statistically by means of different libraries. 


\section{Results}

Prior to the development of the study, a correlation analysis has been carried out, as shown in Table 1. As it can be seen, there is a clear relationship between last year's GDP per capita and this year's GDP per capita.

The rest of the correlations are not considered to be as strong, nevertheless, the most significant relationship is between this year's GDP per capita and the desib variable, which stands at 0.624592 .

Strong correlation would imply multicollinearity between the explanatory variables of our model. Given that it is not the case, as the correlation between the chosen set of variables is not strong, it has been possible to continue with the estimation of the proposed model.

Table 2 illustrates the developed model, where it is possible to see that this year, there is a clear implication of the desic and desid variables in the GDP per capita indicator. In addition, last year's GDP per capita has had a logical impact on this year's GDP per capita, which is positive.

It is important to note that the implication of the variables of the DESI index is positive, and it occurs due to the use of internet services by citizens and due to the implementation of digital technology in businesses.

Table 1. Correlation analysis.

$\begin{array}{lrrrrrrr} & \text { PIBPC } & \text { PIBAN } & \text { desia } & \text { desib } & \text { desic } & \text { desid } & \text { desie } \\ \text { PIBPC } & 1.000000 & 0.994836 & 0.481729 & 0.624592 & 0.299778 & 0.292481 & -0.004682 \\ \text { PIBAN } & 0.994836 & 1.000000 & 0.482999 & 0.621272 & 0.298734 & 0.270716 & -0.024390 \\ \text { desia } & 0.481729 & 0.482999 & 1.000000 & 0.577137 & 0.714044 & 0.485058 & 0.371132 \\ \text { desib } & 0.624592 & 0.621272 & 0.577137 & 1.000000 & 0.511841 & 0.432595 & 0.438125 \\ \text { desic } & 0.299778 & 0.298734 & 0.714044 & 0.511841 & 1.000000 & 0.259130 & 0.387760 \\ \text { desid } & 0.292481 & 0.270716 & 0.485058 & 0.432595 & 0.259130 & 1.000000 & 0.487801 \\ \text { desie } & -0.004682 & -0.024390 & 0.371132 & 0.438125 & 0.387760 & 0.487801 & 1.000000\end{array}$


Javier Parra et al. I The importance of digital transformation. Incidence of The Digital Economy...

Table 2. Regression analysis.

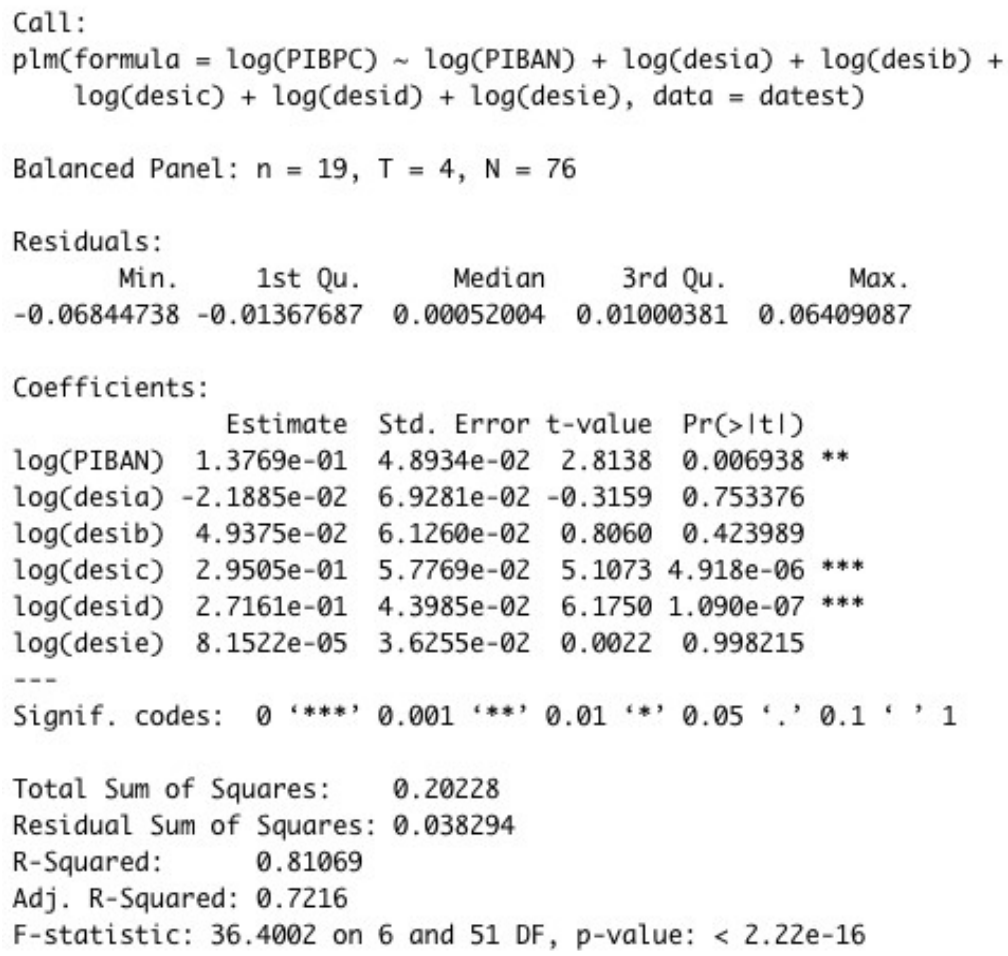

\section{Conclusions}

In developed economies, specifically in the economies whose main driver is technology, different studies have aimed to determine the implication that technological development has in the labor market. However, not many studies have associated GDP per capita with technological development indicators.

According to the results of the conducted study, there is a close relationship between technological indicators and the GDP per capita, especially in terms of the use of Internet services by citizens and the digitalization of businesses.

This result makes one think about the importance of technological development for a country, given that an increase in technology in different fields implies growth in GDP per capita. 
Future lines of research will focus on determining why developed countries have better technology and it will look at the percentage of technological investment in different countries. In addition, it will be analyzed whether the implementation of high-tech in Europe's less developed countries will foster a process of convergence among all European regions.

\section{Acknowledgement}

This article has been funded under the EP - INTERREG V operating program

To Spain Portugal (POCTEP) with the DISRUPTIVE project «Dynamization of the Digital Innovation Hubs within the PocTep region for the promotion of disruptive and next-generation ICTs through cooperation in the cross-border region», in call 2, with the identifier (2291).

\section{References}

1. Arnold, C., Kiel, D., \& Voigt, K. I. (2016). How the industrial internet of things changes business models in different manufacturing industries. International Journal of Innovation Management, 20 (08), 1640015.

2. Corchado, J. M., \& Lees, B. (1998). Cognitive models for integrating artificial intelligence approaches. In AII WORKSHOP ON KNOWLEDGE DISCOVERY. GLASGOW, UK.

3. Corchado, J. M. (1997). Real time forecast with intelligent systems: Cbrs and anns. In WORKSHOP ON ARTIFICIAL NEURAL NETWORKS. ABERDEEN (pp. $1-3)$.

4. Casado-Vara, R., Prieto, J., De la Prieta, F., \& Corchado, J. M. (2018). How blockchain improves the supply chain: Case study alimentary supply chain. Procedia computer science, 134, 393-398.

5. Corchado, J. M. (1996). Case-base reasoning recommendation system. In IEEE COLLOQUIUM ON KNOWLEDGE DISCOVERY. LONDON, UK.

6. Corchado, J. M. (1995). Neuro-symbolic reasoning-a solution for complex problemas. In INTERNATIONAL CONFERENCE ON INTELLIGENT SYSTEMS. LONDON, UK.

7. Corchado, J. M. (1995). Multi agent tools: a case study. In IEEE COLLOQUIUM ON KNOWLEDGE DISCOVERY. LONDON ENGLAND, UK. 
8. Casado-Vara, R., Prieto-Castrillo, F., \& Corchado, J. M. (2018). A game theory approach for cooperative control to improve data quality and false data detection in WSN. International Journal of Robust and Nonlinear Control, 28(16), 50875102.

9. Corchado, J. M., \& Lees, B. (2001). Adaptation of cases for case based forecasting with neural network support. In Soft computing in case based reasoning (pp. 293-319). Springer, London.

10. Rodriguez, J. M. C. (2000). Neuro-symbolic model for real-time forecasting problems (Doctoral dissertation, University of Paisley).

11. Casado-Vara, R., Chamoso, P., De la Prieta, F., Prieto, J., \& Corchado, J. M. (2019). Non-linear adaptive closed-loop control system for improved efficiency in IoT-blockchain management. Information Fusion, 49, 227-239.

12. Li, T., Sun, S., Corchado, J. M., \& Siyau, M. F. (2014, July). Random finite setbased Bayesian filters using magnitude-adaptive target birth intensity. In 17 th International Conference on Information Fusion (FUSION) (pp. 1-8). IEEE.

13. Rodríguez, S., Gil, O., De La Prieta, F., Zato, C., Corchado, J. M., Vega, P., \& Francisco, M. (2010, May). People detection and stereoscopic analysis using MAS. In 2010 IEEE 14th International Conference on Intelligent Engineering Systems (pp. 159-164). IEEE.

14. Guillén, J. H., del Rey, A. M., \& Casado-Vara, R. (2019). Security Countermeasures of a SCIRAS Model for Advanced Malware Propagation. IEEE Access, 7, $135472-135478$.

15. Corchado, J. M. (1996). Artificial intelligence models: composed systems as a solution. In IEEE COLLOQUIUM ON KNOWLEDGE DISCOVERY. LONDON ENGLAND, UK.

16. Casado-Vara, R., De la Prieta, F., Rodriguez, S., Prieto, J., \& Corchado, J. M. (2018, June). Cooperative Algorithm to Improve Temperature Control in Recovery Unit of Healthcare Facilities. In International Symposium on Distributed Computing and Artificial Intelligence (pp. 49-62). Springer, Cham.

17. Corchado, J. M. (1995). Hybrid cbr system for real-time temperature forecasting in the ocean. In IEEE COLLOQUIUM ON KNOWLEDGE DISCOVERY. LONDON, UK.

18. Corchado, J. M. (1995). A distributed recommendation system assos. In IEEE COLLOQUIUM ON KNOWLEDGE DISCOVERY. IEE, LONDON, UK.

19. Corchado, J. M. (1995). The use of kernel methods in cbr systems. In INTERNATIONAL CONFERENCE ON INTELLIGENT SYSTEMS. LONDON ENGLAND UK. 
Javier Parra et al. / The importance of digital transformation. Incidence of The Digital Economy...

20. Corchado, J. M. (1995). Case based reasoning systems: automatic construction. In INTERNATIONAL CONFERENCE ON INTELLIGENT SYSTEMS. LONDON ENGLAND UK.

21. Casado-Vara, R., de la Prieta, F., Prieto, J., \& Corchado, J. M. (2018, November). Blockchain framework for Io'T data quality via edge computing. In Proceedings of the 1st Workshop on Blockchain-enabled Networked Sensor Systems (pp. 19-24). ACM.

22. Gil, A. B., De la Prieta, F., \& Rodríguez, S. (2011). Automatic Learning Object Extraction and Classification in Heterogeneous Environments. In Highlights in Practical Applications of Agents and Multiagent Systems (pp. 109-116). Springer, Berlin, Heidelberg.

23. Rodríguez, S., Tapia, D. I., Sanz, E., Zato, C., de la Prieta, F., \& Gil, O. (2010, July). Cloud computing integrated into service-oriented multi-agent architecture. In International Conference on Information Technology for Balanced Automation Systems (pp. 251-259). Springer, Berlin, Heidelberg.

24. Di Mascio, T., Vittorini, P., Gennari, R., Melonio, A., De La Prieta, F., \& Alrifai, M. (2012, July). The Learners' User Classes in the TERENCE Adaptive Learning System. In 2012 IEEE 12th International Conference on Advanced Learning Technologies (pp. 572-576). IEEE.

25. Mazuelas, S., Lorenzo, R. M., Bahillo, A., Fernández, P., Prieto, J., \& Abril, E. J. (2010). Topology Assessment Provided by Weighted Barycentric Parameters in Harsh Environment Wireless Location Systems. IEEE Transactions on Signal Processing, 58(7), 3842-3857. doi:10.1109/TSP.2010.2047394

26. Prieto, J., Alonso, A. A., la Rosa, de, R., \& Carrera, A. (2014). Adaptive Framework for Uncertainy Analysis in Electromagnetic Field Measurements. Radiation Protection Dosimetry. doi:10.1093/rpd/ncu260

27. Prieto, J., Bahillo, A., Mazuelas, S., Blas, J., Fernández, P., \& Lorenzo, R. M. (2008). RTS/CTS mechanism with IEEE 802.11 for indoor location. Presented at the NAV08/ILA37, The Navigation Conference \& Exhibition.

28. Prieto, J., Bahillo, A., Mazuelas, S., Fernández, P., Lorenzo, R. M., \& Abril, E. J. (2012a). Self-Calibration of TOA/Distance Relationship for Wireless Localization in Harsh Environments. Presented at the 2012 IEEE International Conference on Communications (ICC 2012).

29. Prieto, J., Bahillo, A., Mazuelas, S., Lorenzo, R. M., Blas, J., \& Fernández, P. (2009a). Adding indoor location capabilities to an IEEE 802.11 WLAN using real-time RTT measurements (pp. 113-119). IEEE Press. Retrieved from http:// dl.acm.org/citation.cfm? $\mathrm{id}=1689059.1689083 \&$ coll $=\mathrm{DL} \& \mathrm{dl}=\mathrm{GUIDE} \& \mathrm{CFID}=$ $647274630 \&$ CFTOKEN $=45917612$ 
30. Bullon, Juan, et al. «Manufacturing processes in the textile industry. Expert Systems for fabrics production.» ADCAIJ: Advances in Distributed Computing and Artificial Intelligence Journal 6.4 (2017): 15-23.

31. Souza de Castro, Lucas Fernando, Gleifer Vaz Alves, and André Pinz Borges. «Using trust degree for agents in order to assign spots in a Smart Parking.» (2017).

32. Moung, Ervin. «A Comparison of the YCBCR Color Space with Gray Scale for Face Recognition for Surveillance Applications.» ADCAIJ: Advances in Distributed Computing and Artificial Intelligence Journal [Online], 6.4 (2017): 25-33.

33. Kethareswaran, V., \& C. SANKAR RAM. «An Indian Perspective on the adverse impact of Internet of Things (IoT).» ADCAIJ: Advances in Distributed Computing and Artificial Intelligence Journal 6.4 (2017): 35-40.

34. Cunha, Rafhael, Cleo Billa, \& Diana Adamatti. «Development of a Graphical Tool to integrate the Prometheus AEOlus methodology and Jason Platform.» ADCAIJ: Advances in Distributed Computing and Artificial Intelligence Journal 6.2 (2017): 57-70.

35. Farias, Giovani Parente, et al. «Predicting Plan Failure by Monitoring Action Sequences and Duration.» ADCAIJ: Advances in Distributed Computing and Artificial Intelligence Journal 6.4 (2017): 55-69.

36. Crespo-Ramos, M. J., Machón-González, I., López-García, H., \& Calvo-Rolle, J. L. (2013). Detection of locally relevant variables using SOM-NG algorithm. Engineering Applications of Artificial Intelligence, 26(8), 1992-2000.

37. Casado-Vara, R., Martin-del Rey, A., Affes, S., Prieto, J., \& Corchado, J. M. (2020). IoT network slicing on virtual layers of homogeneous data for improved algorithm operation in smart buildings. Future Generation Computer Systems, 102, 965-977.

38. Mateen, Abdul, et al. «Secure data access control with perception reasoning.» ADCAIJ: Advances in Distributed Computing and Artificial Intelligence Journal 7.1 (2018): 13-28.

39. Teixeira, Eduardo Porto, Eder Goncalves, \& Diana F. Adamatti. «Ulises: A AgentBased System For Timbre Classification.» ADCAIJ: Advances in Distributed Computing and Artificial Intelligence Journal 7.1 (2018): 29-40.

40. Machón-González, I., López-García, H., \& Calvo-Rolle, J. L. (2010, July). A hybrid batch SOM-NG algorithm. In The 2010 international joint conference on neural networks (IJCNN) (pp. 1-5). IEEE.

41. Casteleiro-Roca, J. L., Pérez, J. A. M., Piñón-Pazos, A. J., Calvo-Rolle, J. L., \& Corchado, E. (2015). Modeling the electromyogram (EMG) of patients undergoing anesthesia during surgery. In 10th international conference on soft computing 
models in industrial and environmental applications (pp. 273-283). Springer, Cham.

42. De Melo, Maximilian Jaderson, et al. «Robust and adaptive chatter free formation control of wheeled mobile robots with uncertainties.» ADCAIJ: Advances in Distributed Computing and Artificial Intelligence Journal 7.2 (2018): 27-42.

43. Ribeiro, Catarina, et al. «Customized normalization clustering meth-odology for consumers with heterogeneous characteristics.» ADCAIJ: Advances in Distributed Computing and Artificial Intelligence Journal 7.2 (2018): 53-69.

44. Becerril, Anahiby Anyel. «The value of our personal data in the Big Data and the Internet of all Things Era.» ADCAIJ: Advances in Distributed Computing and Artificial Intelligence Journal 7.2 (2018): 71-80.

45. Garcia, Ana Cristina Bicharra, \& Adriana Santarosa Vivacqua. «ACoPla: a Multiagent Simulator to Study Individual Strategies in Dynamic Situations.» ADCAIJ: Advances in Distributed Computing and Artificial Intelligence Journal 7.2: 81-91.

46. Casado-Vara, R., Novais, P., Gil, A. B., Prieto, J., \& Corchado, J. M. (2019). Distributed continuous-time fault estimation control for multiple devices in IoT networks. IEEE Access, 7, 11972-11984.

47. Jörg Bremer, Sebastian Lehnhoff. (2017) Decentralized Coalition Formation with Agent-based Combinatorial Heuristics. ADCAIJ: Advances in Distributed Computing and Artificial Intelligence Journal (ISSN: 2255-2863), Salamanca, v. 6, n. 3

48. Rafael Cauê Cardoso, Rafael Heitor Bordini. (2017) A Multi-Agent Extension of a Hierarchical Task Network Planning Formalism. ADCAIJ: Advances in Distributed Computing and Artificial Intelligence Journal (ISSN: 2255-2863), Salamanca, v. 6, n. 2

49. Enyo Gonçalves, Mariela Cortés, Marcos De Oliveira, Nécio Veras, Mário Falcão, Jaelson Castro (2017). An Analysis of Software Agents, Environments and Applications School: Retrospective, Relevance, and Trends. ADCAIJ: Advances in Distributed Computing and Artificial Intelligence Journal (ISSN: 2255-2863), Salamanca, v. 6, n. 2

50. Eduardo Porto Teixeira, Eder M. N. Goncalves, Diana F. Adamatti (2017). Ulises: A Agent-Based System For Timbre Classification. ADCAIJ: Advances in Distributed Computing and Artificial Intelligence Journal (ISSN: 2255-2863), Salamanca, v. 6, n. 2

51. Lucas Fernando Souza de Castro, Gleifer Vaz Alves, André Pinz Borges (2017). Using trust degree for agents in order to assign spots in a Smart Parking. ADCAIJ: Advances in Distributed Computing and Artificial Intelligence Journal (ISSN: 2255-2863), Salamanca, v. 6, n. 2 
52. Aversa, R., Petrescu, R. V., Akash, B., Bucinell, R., Corchado, J., Berto, F., ... \& Petrescu, F. I. (2017). Kinematics and forces to a new model forging manipulator. American Journal of Applied Sciences, 14(1), 60-80.

53. Li, T., Sun, S., Bolić, M., \& Corchado, J. M. (2016). Algorithm design for parallel implementation of the SMC-PHD filter. Signal Processing, 119, 115-127.

54. Corchado, J. M., Aiken, J., Corchado, E. S., \& Fdez-Riverola, F. (2005). Evaluating the air-sea interactions and fluxes using an instance-based reasoning system. AI Communications, 18(4), 247-256.

55. Costa, Â., Novais, P., Corchado, J. M., \& Neves, J. (2011). Increased performance and better patient attendance in an hospital with the use of smart agendas. Logic Journal of IGPL, 20(4), 689-698.

56. Rodríguez, S., de La Prieta, F., Tapia, D. I., \& Corchado, J. M. (2010, June). Agents and computer vision for processing stereoscopic images. In International Conference on Hybrid Artificial Intelligence Systems (pp. 93-100). Springer, Berlin, Heidelberg.

57. Corchado, J. M., Corchado, E. S., \& Pellicer, M. A. (2004, September). Design of cooperative agents for mobile devices. In International Conference on Cooperative Design, Visualization and Engineering (pp. 205-212). Springer, Berlin, Heidelberg.

58. Corchado, J. M., Laza, R., Borrajo, L., Yañez, J. C., De Luis, A., \& Gonzalez-Bedia, M. (2003, July). Agent-based web engineering. In International Conference on Web Engineering (pp. 17-25). Springer, Berlin, Heidelberg.

59. Fdez-Riverola, F., \& Corchado, J. M. (2003). Forecasting red tides using an hybrid neuro-symbolic system. AI Communications, 16(4), 221-233.

60. González-Briones, A., Prieto, J., De La Prieta, F., Herrera-Viedma, E., \& Corchado, J. (2018). Energy optimization using a case-based reasoning strategy. Sensors, 18(3), 865.

61. Díaz, F., Fdez-Riverola, F., Glez-Peña, D., \& Corchado, J. M. (2006, September). Using fuzzy patterns for gene selection and data reduction on microarray data. In International Conference on Intelligent Data Engineering and Automated Learning (pp. 1087-1094). Springer, Berlin, Heidelberg.

62. Koetsier, J., Corchado, E., MacDonald, D., Corchado, J., \& Fyfe, C. (2004, June). Kernel maximum likelihood hebbian learning. In International Conference on Computational Science (pp. 650-653). Springer, Berlin, Heidelberg.

63. Pavón, J., \& Corchado, J. (2004). Agents for the web. International journal of Web engineering and technology, 1(4), 393-396.

64. Fdez-Riverola, F., Díaz, F., Borrajo, M. L., Yáñez, J. C., \& Corchado, J. M. (2005, August). Improving gene selection in microarray data analysis using fuzzy patterns 
inside a cbr system. In International Conference on Case-Based Reasoning (pp. 191-205). Springer, Berlin, Heidelberg.

65. Fernández-Riverola, F., \& Corchado, J. M. (2003, November). Employing tsk fuzzy models to automate the revision stage of a cbr system. In Conference on Technology Transfer (pp. 302-311). Springer, Berlin, Heidelberg.

66. Corchado, J. M., \& Aiken, J. (1998). Expert system for modelling water masses. In WORKSHOP ON DATA MINING. GLASGOW, SCOTLAND.

67. Corchado, J. M., \& Aiken, J. (1998). Neuro-symbolic reasoning for real time oceanographic problems. In CONFERENCE ON DATA MINING. IEE, SAVOY PLACE, LONDON.

68. Corchado, J. M. (1998). Models for integrating artificial intelligence approaches. DOCTORAL CONSORTIUM ON KNOWLEDGE DISCOVERY AND DATA MINING. PAISLEY, UK.

69. Borrajo, M. L., Corchado, J. M., Yáñez, J. C., Fdez-Riverola, F., \& Díaz, F. (2005, August). Autonomous internal control system for small to medium firms. In International Conference on Case-Based Reasoning (pp. 106-121). Springer, Berlin, Heidelberg.

70. Fdez-Riverola, F., Díaz, F., \& Corchado, J. M. (2004, November). Applying rough sets reduction techniques to the construction of a fuzzy rule base for case based reasoning. In Ibero-American Conference on Artificial Intelligence (pp. 83-92). Springer, Berlin, Heidelberg.

71. Corchado, J., \& Lees, B. (1998). Case based reasoning opportunities and technologies. In CONFERENCE ON KNOWLEDGE DISCOVERY. IEE, SAVOY PLACE, LONDON.

72. Corchado, J., \& Lees, B. (1998). Artificial neural networks in pattern recognition: multicollinearity and heterocedasticity. In COLLOQUIUM ON KNOWLEDGE DISCOVERY. LONDON, UK.

73. Corchado, J., \& Lees, B. (1998). An overview of intelligent frameworks. In COLLOQUIUM ON INTELLIGENT SYSTEMS. IEE, LONDON, UK.

74. Corchado, J. M., \& Lees, B. (1998). Probis: Modelling intelligence with hybrid systems. In WORKSHOP ON DATA MINING. University of GLASGOW, SCOTLAND, UK.

75. Corchado, J. (1998). Real time forecast with intelligent systems. In CONFERENCE ON KNOWLEDGE DISCOVERY. IEE, SAVOY PLACE, LONDON.

76. Corchado, J. M. (1997). Bdi multiagent hybrid architecture for project management. In IEEE COLLOQUIUM ON KNOWLEDGE DISCOVERY AND DATA MINING. LONDON ENGLAND. 
Javier Parra et al. I The importance of digital transformation. Incidence of The Digital Economy...

77. Corchado, J. M. (1997). System for decision making: a practical case. In CONFERENCE ON KNOWLEDGE DISCOVERY AND DATA MINING. IEE, LONDON, UK.

78. Corchado, J. (1995). Cbr systems, an overview. In INTERNATIONAL CONFERENCE ON INTELLIGENT SYSTEMS. LONDON, ENGLAND, UK. 